\title{
Electron and Ion Temperatures-A Comparison of Ground-Based Incoherent Scatter and AE-C Satellite Measurements
}

\author{
R. F. Benson, ${ }^{1}$ P. Bauer, ${ }^{2}$ L. H. Brace, ${ }^{1}$ H. C. Carlson, ${ }^{3}$ J. Hagen, ${ }^{4}$ W. B. Hanson, ${ }^{3}$ \\ W. R. HOEgY, ${ }^{1}$ M. R. TORR, ${ }^{5}$ R. H. WAND, ${ }^{\circ}$ AND V. B. WICKWAR ${ }^{7}$
}

\begin{abstract}
The Atmosphere Explorer-C satellite (AE-C) is uniquely suited for correlative studies with groundbased stations because its on-board propulsion system enables a desired ground station overflight condition to be maintained for a period of several weeks. It also provides the first low-altitude (below 260 $\mathrm{km}$ ) comparison of satellite and incoherent scatter electron and ion temperatures. More than $40 \mathrm{com}$ parisons of remote and in situ measurements were made by using data from AE-C and four incoherent scatter stations (Arecibo, Chatanika, Millstone Hill, and St. Santin). The results indicate very good agreement between satellite and ground measurements of the ion temperature, the average satellite retarding potential analyzer temperatures differing from the average incoherent scatter temperatures by $-2 \%$ at St. Santin, $+3 \%$ at Millstone Hill, and $+2 \%$ at Arecibo. The electron temperatures also agree well, the average satellite temperatures exceeding the average incoherent scatter temperatures by $3 \%$ at St. Santin, $2 \%$ at Arecibo, and $11 \%$ at Millstone Hill. Several temperature comparisons were made between $\mathrm{AE}-\mathrm{C}$ and Chatanika. In spite of the highly variable ionosphere often encountered at this high-latitude location, good agreement was obtained between the in situ and remote measurements of electron and ion temperatures. Longitudinal variations are found to be very important in the comparisons of electron temperature in some locations. The agreement between the electron temperatures is considerably better than that found in some earlier comparisons involving satellites at higher altitudes.
\end{abstract}

\section{INTRODUCTION}

For more than a decade it has been recognized that the earth's ionosphere is not in thermal equilibrium; i.e., the condition $T_{e}>T_{l}>T_{n}$ is normally encountered in the daytime ionosphere where $T_{e}, T_{l}$, and $T_{n}$ represent the temperatures of the electrons, ions, and neutrals, respectively. Accurate temperature measurements are required in order to understand the energy budget of the earth's atmosphere-ionosphere-magnetosphere system. For example, the heat flux which couples the earth's ionized regions is extremely sensitive to the altitude variation of electron temperature, and a $20 \%$ uncertainty in $T_{e}$ leads to an uncertainty in the heat flux of approximately a factor of 2 .

The most commonly used techniques for measuring $T_{e}$ and $T_{i}$ involve either in situ probe measurements using spacecraft or remote measurements using ground-based incoherent scatter facilities. Numerous comparisons have been conducted in order to gain confidence in the measurements. These comparisons have produced a variety of results. In general, in situ retarding potential analyzer (RPA) measurements of $T_{t}$ appear to show good agreement with the remote ground-based measurements or differ for reasons that are understood, as is discussed below. The comparisons involving electrostatic probe measurements of $T_{e}$, however, have resulted in significant discrepancies, which are still at least partly unexplained.

\footnotetext{
${ }^{1}$ Laboratory for Planetary Atmospheres, NASA Goddard Space Flight Center, Greenbelt, Maryland 20771.

${ }_{2}^{2}$ National Academy of Sciences National Research Council.

${ }^{3}$ University of Texas at Dallas, Richardson, Texas $\grave{75080 .}$

4 Arecibo Observatory, National Astronomy and Ionosphere Center, Arecibo, Puerto Rico 00612.

${ }^{5}$ Space Physics Research Laboratory, University of Michigan, Ann Arbor, Michigan 48105; National Institute for Telecommunications Research of CSIR, Johannesburg, South Africa; National Astronomy and Ionosphere Center, Cornell University, Ithaca, New York 14853.

${ }^{6}$ Lincoln Laboratory, Massachusetts Institute of Technology, Lexington, Massachusetts 02173.

${ }_{7}^{7}$ Stanford Research Institute, Menlo Park, California 94025.
}

Copyright (C) 1977 by the American Geophysical Union.
In some of these instances the ratio of probe temperature $\left(T_{e}\right)_{p}$ to incoherent scatter temperature $\left(T_{e}\right)_{s}$ was as high as $1.7-1.9$ [Hanson et al., 1969; Carlson and Sayers, 1970]. Others have found smaller discrepancies $\left(\left(T_{e}\right)_{p} /\left(T_{e}\right)_{s} \simeq 1.15\right)$ [McClure et al., 1973] or no significant discrepancy [Evans, 1965; Taylor and Wrenn, 1970; Wrenn et al., 1973]. The diversity of these findings may have been due to the lack of simultaneity of the observations and/or to the spatial separation of the ionospheric samples being examined in the different experiments. Comparisons involving rocket-borne electrostatic probes flown in the vicinity of an incoherent scatter station have not indicated a large discrepancy; i.e., $\left(T_{e}\right)_{p} /\left(T_{e}\right)_{s}$ was generally less than 1.2 [Brace et al., 1969; Sagalyn and Wand, 1971], but these comparisons were limited to altitudes below $300 \mathrm{~km}$.

An indication of an altitude dependence was obtained in a rocket probe-incoherent scatter comparison that extended to $700 \mathrm{~km}$ [Brace and McClure, 1971]. Below $350 \mathrm{~km},\left(T_{e}\right)_{p} /\left(T_{e}\right)_{s}$ $\simeq 1.0$, whereas at $700 \mathrm{~km}$ the ratio had attained a value of 1.8 . The results of this experiment, however, may have been influenced by the large separation (nearly $5000 \mathrm{~km}$ ) in longitude between the rocket trajectory and the incoherent scatter beam.

An altitude dependence was also suggested by a related temperature comparison in which simultaneous in situ measurements were made from the same vehicle [Benson, 1973]. In this case, $\left(T_{e}\right)_{p}$ was compared with $T_{e}$ as deduced from the plasma resonances stimulated by the topside sounder on the same vehicle (Alouette 2 ). The resonance temperature, determined by using the technique of Oya and Benson [1972], lies between $\left(T_{e}\right)_{p}$ and $\left(T_{e}\right)_{s}$ and is usually closer to $\left(T_{e}\right)_{s}$ [Benson and Hoegy, 1973]. On the average, $\left(T_{e}\right)_{p}$ is about $10 \%$ larger than the plasma resonance temperature at the lowest altitudes sampled $(\simeq 510 \mathrm{~km})$ and about $40 \%$ larger at higher altitudes $(\simeq 540-610 \mathrm{~km})$.

There have been only two accounts published of detailed comparisons between RPA and incoherent scatter measurements of $T_{i}$. The Ogo 6 RPA measurements of $T_{i}$ agreed with the incoherent scatter data to within a few percent $[\mathrm{McClure}$ et al., 1973], though the comparisons were largely confined to times when the satellite was in eclipse (because of vehicle potential problems). Measurements of $T_{\imath}$ from the Ogo 4

Paper number 6A0678. 

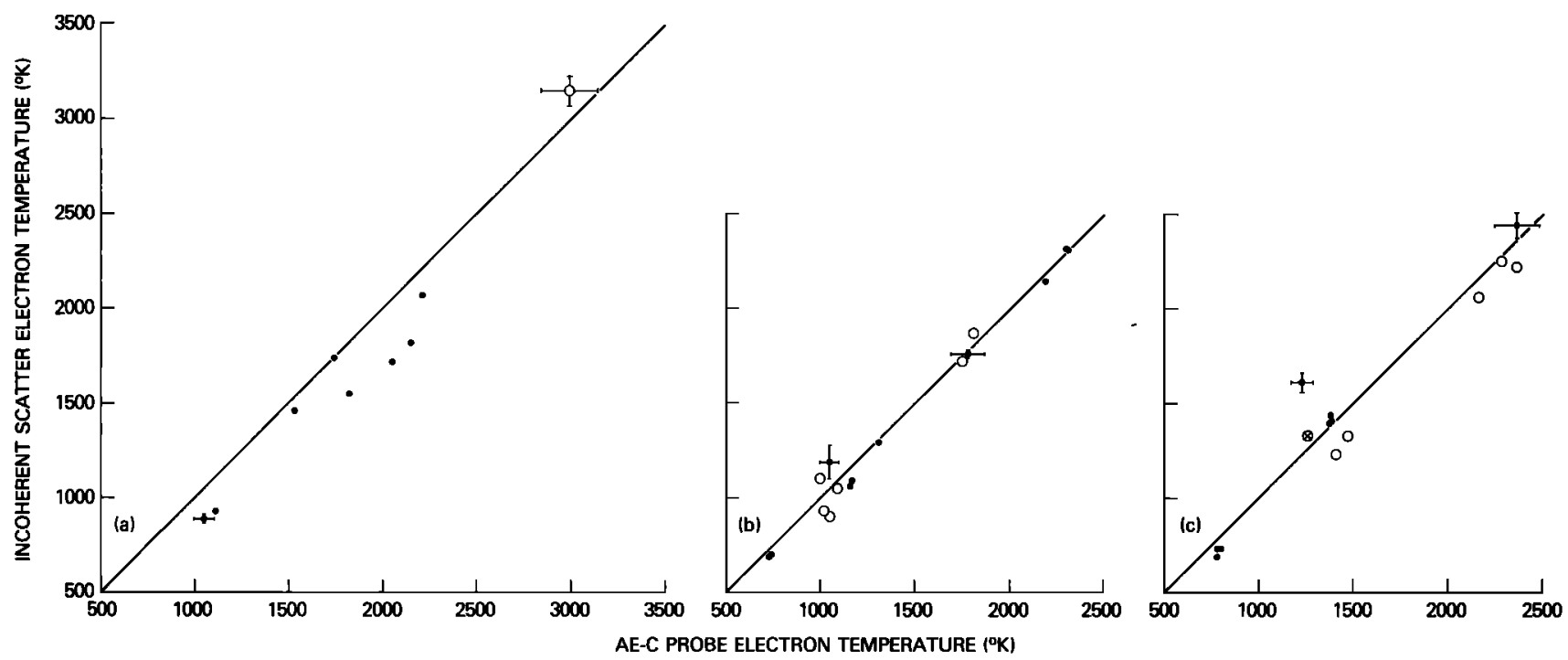

Fig. 1. Comparison of electron temperature measurements based on the AE-C cylindrical electrostatic probe and the incoherent scatter facility at (a) Millstone Hill, $(b)$ St. Santin (the Nancay receiver was used in conjunction with the St. Santin transmitter), and (c) Arecibo. The solid line at $45^{\circ}$ is shown to indicate the one-to-one agreement reference position. The date, local time, position, and measurement uncertainty associated with each point are given in Table 1. The open circles indicate points where $\mid \Delta$ (longitude) $\mid>11^{\circ}$ or where the altitude exceeded $450 \mathrm{~km}$. The open circle with a superimposed cross corresponds to AE-C orbit 3020 in Figure 4.

RPA, however, were consistently higher (by as much as $40 \%$ ) than the incoherent scatter values [McClure and Troy, 1971].

The difference in performance of these two RPA's has been ascribed to the difference in the nature of the grids in their sensors [Hanson et al., 1972; Goldan et al., 1973]. Both the magnitude and the direction of the discrepancy seem to be explained. In effect, the Ogo 4 grids were too coarse to establish equipotential surfaces. When the corrections of Goldan et al. [1973] are applied to the Ogo 4 results, the discrepancy is reduced to less than $10 \%$. The sensor grids used for the AE-C RPA measurements discussed here were designed to be considerably better than those used for the Ogo 6 measurements.

The Atmosphere Explorer-C satellite (AE-C) has provided the first opportunity to make comparisons between low-altitude satellite measurements (below $260 \mathrm{~km}$ ) and ground-based measurements. The on-board propulsion system enables ex- cursions to low altitudes $(130 \mathrm{~km})$ and provides the capability of maintaining a desired orbital track over a ground station for a period of several weeks in order to conduct closely correlated experiments. The AE-C satellite was launched into a $68^{\circ}$ inclination orbit at an altitude ranging from 150 to $4200 \mathrm{~km}$ on December 16, 1973. The orbit was changed to be circular at an altitude of $\sim 250 \mathrm{~km}$ in December 1974 ; it is frequently modified to meet specific goals. See the works by Dalgarno et al. [1973] and Spencer et al. [1973] for a description of the AE mission and spacecraft.

This paper presents the results of comparisons of the AE-C electron temperature $\left(T_{e}\right)_{p}$, determined from the cylindrical electrostatic probe [Brace et al., 1973], and the ion temperature $\left(T_{l}\right)_{\mathbf{R P A}}$, determined from the planar retarding potential analyzer [Hanson et al., 1973], with the electron temperatures $\left(T_{e}\right)_{s}$ and ion temperatures $\left(T_{i}\right)_{s}$ determined from the follow-

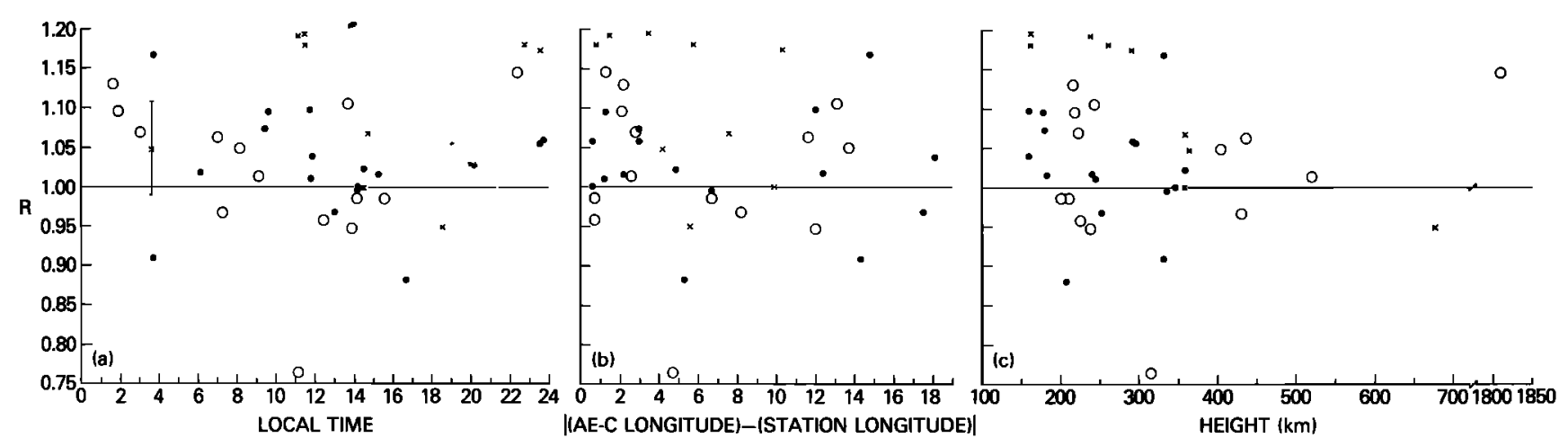

Fig. 2. The ratio $R=\left(T_{e}\right)_{p} /\left(T_{e}\right)_{s}$ as a function of $(a)$ local time, $(b)$ the absolute value of the longitude separation between AE-C and the incoherent scatter station, and $(c)$ the height for Millstone Hill (crosses), St. Santin (solid dots), and Arecibo (open circles). 
ing incoherent scatter facilities with the indicated ground level coordinates: Arecibo $\left(18.4^{\circ} \mathrm{N}, 66.8^{\circ} \mathrm{W}, L=1.4\right)$, St. Santin $\left(44.6^{\circ} \mathrm{N}, 2.2^{\circ} \mathrm{E}, L=1.8\right)$, Millstone Hill $\left(42.6^{\circ} \mathrm{N}, 71.5^{\circ} \mathrm{W}, L=\right.$ 3.1 ), and Chatanika $\left(65.1^{\circ} \mathrm{N}, 147.5^{\circ} \mathrm{W}, L=5.5\right)$. Such comparisons are required before $T_{e}$ and $T_{t}$ measurements, based on the remote and in situ techniques, can be combined to provide reliable information on an event of interest, for example, to extend the altitude temperature profile observed over an incoherent scatter station in latitude by using the satellite data. Since the accuracies of the various measurement techniques probably vary somewhat with geophysical conditions and perhaps independently with time, we should not anticipate finding simple relationships that will account for all the discrepancies found between measurements obtained by different methods.

\section{Observations}

In general, the AE-C and incoherent scatter data were compared at the same local time. The method was to determine the incoherent scatter temperature for the altitude and local time at which AE-C crossed the latitude of the incoherent scatter station. An exception to this method was made in the case of the Chatanika comparisons because the latitude of the station was near the north point of the satellite orbit and the latitude crossing could be far removed from the point of closest approach even on a pass near the station. Thus the point of minimum horizontal distance between AE-C and the intersection of the transmitted beam and the ionosphere at the AE$\mathrm{C}$ altitude was used for the Chatanika comparisons.

Low-and mid-latitude $T_{e}$ comparisons. The results of the $T_{e}$ comparisons between AE-C and Millstone Hill, St. Santin, and Arecibo are presented in Figures $1 a, 1 b$, and $1 c$, respectively. The combined results are presented in Figures $2 a, 2 b$, and $2 c$, where the ratio $R=\left(T_{e}\right)_{p} /\left(T_{e}\right)_{s}$ is plotted against the - local time, the longitude separation between AE-C and the incoherent scatter station, and the height, respectively. In Table 1 the data are related to the AE-C orbit number and the date of the comparison. (Unless indicated otherwise, the errors

TABLE 1. Low-Latitude and Mid-Latitude $T_{e}$ and $T_{i}$ Comparisons

\begin{tabular}{|c|c|c|c|c|c|c|c|c|c|}
\hline \multirow{2}{*}{$\begin{array}{l}\text { AE-C } \\
\text { Orbit }\end{array}$} & \multirow{2}{*}{$\begin{array}{c}\text { Incoherent } \\
\text { Scatter } \\
\text { Station }\end{array}$} & \multicolumn{2}{|c|}{ AE-C Local Time } & \multirow{2}{*}{$\begin{array}{c}\Delta \text { (Longitude) } \\
\text { deg }\end{array}$} & \multirow{2}{*}{$\begin{array}{l}\text { Altitude, } \\
\text { km }\end{array}$} & \multirow{2}{*}{$\begin{array}{l}\left(T_{e}\right)_{p} \\
{ }^{\circ} \mathbf{K}\end{array}$} & \multirow{2}{*}{$\begin{array}{l}\left(T_{e}\right)_{s}, \\
{ }^{\circ} \mathrm{K}\end{array}$} & \multirow{2}{*}{$\begin{array}{l}\left(T_{l}\right)_{\mathrm{RPA}}, \\
{ }^{\circ} \mathrm{K}\end{array}$} & \multirow{2}{*}{$\begin{array}{l}\left(T_{i}\right)_{s}, \\
{ }^{\circ} \mathrm{K}\end{array}$} \\
\hline & & Time & Date & & & & & & \\
\hline 333 & $\mathrm{~S}$ & 1638 & Jan. 15,1974 & 5.3 & 207 & 1050 & $1190 \pm 90$ & & $850 \pm 70$ \\
\hline 410 & $\mathrm{~S}$ & 1516 & Jan. 22,1974 & -2.2 & 182 & 1310 & $1290 \pm 30$ & & $770 \pm 20$ \\
\hline 641 & $\mathrm{~S}^{*}$ & 1155 & Feb. 12, 1974 & 18.1 & 159 & -1090 & $1050 \pm 100$ & & $740 \pm 70$ \\
\hline 653 & $\mathbf{S}^{*}$ & 1144 & Feb. 13, 1974 & -12.0 & 159 & 1020 & $930 \pm 70$ & & $680 \pm 50$ \\
\hline 797 & $\mathrm{~S}$ & 0936 & Feb. 26, 1974 & -1.3 & 177 & 1160 & $1060 \pm 30$ & & $660 \pm 20$ \\
\hline 808 & $\mathbf{S}$ & 0925 & Feb. 27, 1974 & 3.0 & 179 & 1170 & $1090 \pm 30$ & & $670 \pm 20$ \\
\hline 1032 & $\mathbf{S}^{*}$ & 0606 & March 19, 1974 & -12.4 & 241 & 1750 & $1720 \pm 20$ & 700 & $700 \pm 10$ \\
\hline 1197 & $S^{*}$ & 0342 & April 3, 1974 & -14.8 & 332 & 1050 & $900 \pm 30$ & & $880 \pm 30$ \\
\hline 1208 & $\mathbf{S}^{*}$ & 0341 & April 4, 1974 & -14.3 & 331 & 1000 & $1100 \pm 100$ & & $780 \pm 70$ \\
\hline 1493 & $\mathbf{S}$ & 1430 & April 29, 1974 & -4.9 & 359 & 2190 & $2140 \pm 20$ & 940 & $960 \pm 10$ \\
\hline 1504 & $\mathbf{S}$ & 1413 & April 30,1974 & 0.6 & 347 & 2310 & $2310 \pm 20$ & 920 & $940 \pm 10$ \\
\hline 1664 & $\mathbf{S}$ & 1147 & May 14,1974 & 1.2 & 244 & 1780 & $1760 \pm 20$ & 940 & $930 \pm 10$ \\
\hline 4484 & $\mathbf{S}$ & 2336 & Dec. 10,1974 & 3.0 & 296 & 740 & $700 \pm 20$ & 660 & $700 \pm 20$ \\
\hline 4500 & $\mathbf{S}$ & 2340 & Dec. 11,1974 & 0.6 & 293 & 730 & $690 \pm 10$ & 680 & $690 \pm 10$ \\
\hline 4510 & $\mathbf{S}$ & 1411 & Dec. 12,1974 & 6.7 & 341 & 2300 & $2310 \pm 50$ & 820 & $860 \pm 30$ \\
\hline 5071 & $\mathbf{S}^{*}$ & 1301 & Jan. 16, 1975 & 17.5 & 252 & 1810 & $1870 \pm 20$ & 810 & $810 \pm 10$ \\
\hline 666 & $\mathbf{M}$ & 1130 & Feb. 14, 1974 & 0.8 & 161 & 1050 & $890 \pm 20$ & & $740 \pm 20$ \\
\hline 677 & $\mathbf{M}$ & 1129 & Feb. 15,1974 & 3.5 & 162 & 1110 & $930 \pm 20$ & & $710 \pm 20$ \\
\hline 1206 & $\mathbf{M}^{*}$ & 1832 & April 3, 1974 & -5.6 & 677 & 2990 & $3150 \pm 80$ & 1990 & $1830 \pm 100$ \\
\hline 1210 & $\mathbf{M}$ & 0336 & April 4, 1974 & -4.2 & 364 & 1530 & $1460 \pm 40$ & 980 & $990 \pm 50$ \\
\hline 1701 & $\mathbf{M}$ & 1109 & May 17,1974 & 1.5 & 238 & 2050 & $1720 \pm 30$ & & $1000 \pm 30$ \\
\hline 4482 & $\mathbf{M}$ & 1442 & Dec. 10,1974 & -7.6 & 359 & $\cdot 2210$ & $2070 \pm 40$ & 910 & $910 \pm 30$ \\
\hline 4487 & $\mathbf{M}$ & 2332 & Dec. 10,1974 & 10.3 & 291 & $1820 \pm 10 \%$ & $550 \pm 40$ & 750 & $790 \pm 30$ \\
\hline 4498 & $\mathbf{M}$ & 1414 & Dec. 11,1974 & -9.9 & 358 & 1740 & $1740 \pm 50$ & 910 & $790 \pm 40$ \\
\hline 4535 & $\mathbf{M}$ & 2241 & Dec. 14,1974 & 5.8 & 262 & $2150 \pm 10 \%$ & $1820 \pm 30$ & 780 & $830 \pm 30$ \\
\hline 895 & $A^{*}$ & 2221 & March 7, 1974 & 1.3 & 1811 & $1410 \pm 15 \%$ & $1230 \pm 60$ & $1240 \pm 5 \%$ & $1230 \pm 60$ \\
\hline 911 & $A^{*}$ & 0907 & March 8, 1974 & 2.6 & 521 & 2280 & $2250 \pm 150$ & 1470 & $1520 \pm 100$ \\
\hline 3020 & $A^{*}$ & 1352 & Sept. 1, 1974 & 12.0 & 238 & 1260 & $1330 \pm 70$ & 900 & $880 \pm 40$ \\
\hline 3033 & $\mathrm{~A}^{*}$ & 1340 & Sept. 2, 1974 & 13.1 & 243 & 1470 & $1330 \pm 70$ & 960 & $880 \pm 40$ \\
\hline 3192 & A & 1109 & Sept. 14,1974 & -4.7 & 315 & 1230 & $1610 \pm 50$ & 920 & $860 \pm 20$ \\
\hline 3382 & $A^{*}$ & 0807 & Sept. 28,1974 & -13.7 & 404 & 2160 & $2060 \pm 50$ & 920 & $780 \pm 20$ \\
\hline 3437 & A & 0714 & Oct. 2,1974 & -8.2 & 431 & 2360 & $2440 \pm 70$ & 950 & $900 \pm 20$ \\
\hline 3451 & $A^{*}$ & 0700 & Oct. 3, 1974 & -11.6 & 437 & 2360 & $2220 \pm 30$ & & $820 \pm 10$ \\
\hline 6353 & A & 1534 & April 5, 1975 & -6.7 & 209 & 1380 & $1400 \pm 130$ & 830 & $840 \pm 40$ \\
\hline 6433 & A & 1408 & April 10, 1975 & 0.7 & 200 & 1380 & $1400 \pm 130$ & 850 & $830 \pm 30$ \\
\hline 6442 & $\mathbf{A}$ & 0301 & April 11, 1975 & 2.8 & 223 & 780 & $730 \pm 40$ & 740 & $730 \pm 40$ \\
\hline 6506 & A & 0153 & April 15,1975 & 2.1 & 218 & 800 & $730 \pm 30$ & 750 & $730 \pm 30$ \\
\hline 6522 & A & 0136 & April 16, 1975 & 2.2 & 216 & 780 & $690 \pm 30$ & 720 & $690 \pm 30$ \\
\hline 6529 & A & 1226 & April 16,1975 & 0.7 & 226 & 1380 & $1440 \pm 30$ & 790 & $810 \pm 20$ \\
\hline
\end{tabular}

$\Delta$ (longitude) is the longitude difference (longitude of the AE-C subsatellite point minus longitude of the incoherent scatter station) at the point where AE-C crosses the latitude of the incoherent scatter station.

$S$ stands for St. Santin, M for Millstone Hill, and A for Arecibo.

*Points plotted as open circles in Figure 1. 

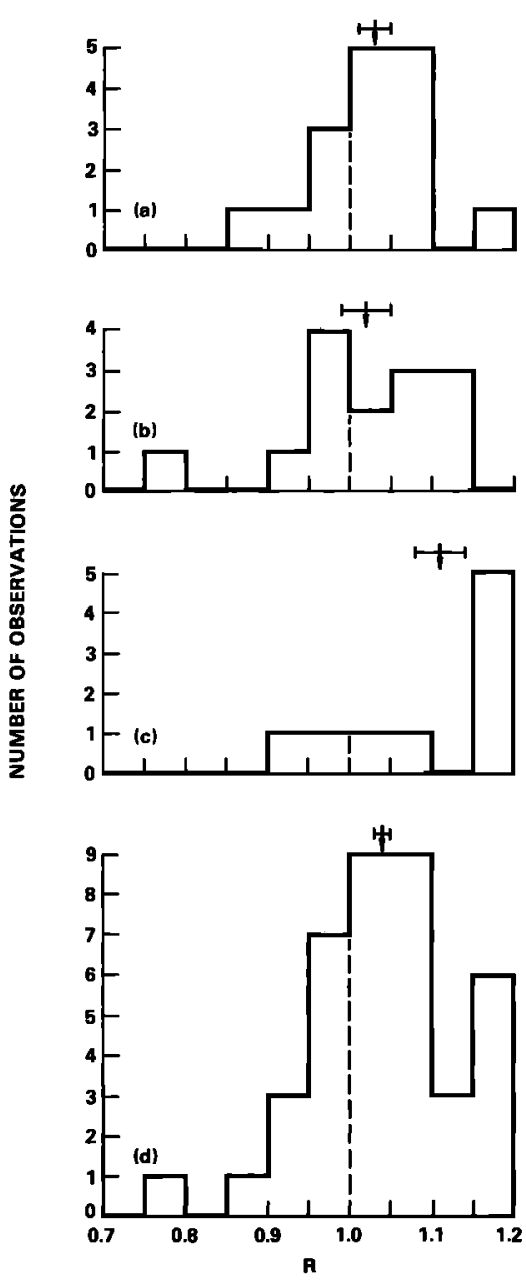

Fig. 3. Histograms showing the distribution of $R=\left(T_{e}\right)_{p} /\left(T_{e}\right)_{a}$ in the comparisons using data from AE-C and $(a)$ St. Santin, $(b)$ A recibo, (c) Millstone Hill, and (d) the above three stations combined. The vertical arrows with error bars indicate $\bar{R} \pm \sigma /(n)^{1 / 2}$. The values are $1.03 \pm 0.02$ at St. Santin, $1.02 \pm 0.03$ at Arecibo, $1.11 \pm 0.03$ at Millstone Hill, and $1.04 \pm 0.01$ in the combined data set.

associated with $\left(T_{e}\right)_{p}$ and $\left(T_{i}\right)_{\mathrm{RPA}}$ are $5 \%$ and $2 \%$, respectively. The errors associated with $\left(T_{e}\right)_{s}$ and $\left(T_{i}\right)_{s}$ reflect the uncertainties estimated in the spatial interpolations and extrapolations required to compare the measurements with the satellite measurements; these error estimates have all been rounded to the next highest $10^{\circ}$. All of the individual measurements of $T_{e}$ and $T_{i}$ have been rounded to the nearest $10^{\circ}$.) The data are fairly well distributed in local time (Figure $2 a$ ). Even though comparisons were made with the longitude separation between the subsatellite point and the incoherent station being as large as $18^{\circ}$, no variation of $R$ with the longitude separation was observed (Figure $2 b$ ). Most of the comparisons were conducted at a relatively low altitude, nearly half of them below $250 \mathrm{~km}$ and all but three of them below $450 \mathrm{~km}$ (Figure $2 \mathrm{c}$ ). The altitude dependence referred to in the introduction was not evident over the altitude range of this data set. The average value of $R$ and the corresponding standard deviation of the mean are shown on the histogram for each station in Figures $3 a-3 c$ and on the histogram for the combined data from all three stations in Figure 3d. On the average, $\left(T_{e}\right)_{p}>\left(T_{e}\right)_{s}$ by $3 \%$ at St. Santin, $2 \%$ at Arecibo, and $11 \%$ at Millstone Hill (see Figures $3 a-3 c$ ).
If the data from all of the stations are averaged together (as has been done in previous comparisons), then the probe electron temperature exceeds the incoherent scatter temperature by $4 \%$ (Figure $3 d$ ). This departure of $R$ from unity is less than the value found in many of the earlier studies. The present results, however, indicate that it is more meaningful to consider the comparisons involving different incoherent scatter stations separately, since significant differences can be observed between the stations. These differences may be due in part to real differences in the geophysical conditions at the various stations. For example, Millstone Hill and St. Santin are at similar geographic latitudes but at quite different magnetic latitudes. The ionosphere above Millstone Hill corresponds to $L=3.2$, at an altitude of $300 \mathrm{~km}$, which is in the vicinity of the magnetic field lines passing through the plasmapause, whereas St. Santin $(L=1.8)$ is at a relatively low magnetic latitude. Thus one could expect quite different ionospheric conditions at these two locations. These differences could lead to different probe and scatter electron temperatures. For example, Hoegy [1971] has shown that a nonMaxwellian distribution of electron velocities could produce such an effect.

Evidence for a longitudinal variation in $T_{e}$ can be obtained by comparing data from several consecutive AE-C passes. Since the local time corresponding to the satellite crossing of a given latitude remains nearly constant during these passes, any difference in the probe temperature must be attributed either to a universal time effect or to a longitudinal depéridence. An opportunity to investigate this longitudinal dependence was available for one of the AE-C-A recibo points of comparison, and the results are presented in Figure 4. The lowest point on the figure corresponds to the cross plotted in Figure $1 c$. If it is assumed that the variation in $\left(T_{e}\right)_{p}$ is entirely due to a longitudinal dependence rather than to changes caused by the different universal times involved ( $K p=3$ during the 3-hour interval of interest, and the magnetic activity for the day was only slightly greater than the average for the month) and if a linear interpolation is used between the data points in Figure 4, then $\left(T_{e}\right)_{p}$ corresponding to the longitude of Arecibo would be $70^{\circ} \mathrm{K}$ greater than the value plotted in Figure $1 c$ and would be in very good agreement with $\left(T_{e}\right)_{s}$. The purpose of the presentation of Figure 4 is to emphasize the importance of direct overflights in comparing $\left(T_{e}\right)_{D}$ and $\left(T_{e}\right)_{s}$, and it is not intended to imply that all of the differences would disappear if longitu-

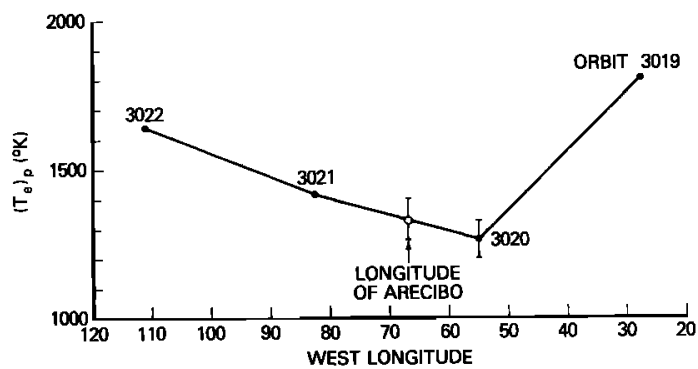

Fig. 4. Longitudinal variation of $\left(T_{e}\right)_{p}$ in the vicinity of Arecibo as determined from four consecutive orbits of AE-C. The temperature deduced from orbit 3020 was combined with the Arecibo temperature to produce one of the points (the open circle with the cross) of Figure 1c. This AE-C temperature determination corresponds to 1754 UT (1352 LT) on September 1, 1974. The difference in universal time between the points is equal to the AE-C period of $110 \mathrm{~min}$; the difference in local time is less than $1 \mathrm{~min}$. The open circle at the longitude of Arecibo indicates the incoherent scatter $T_{e}$. 


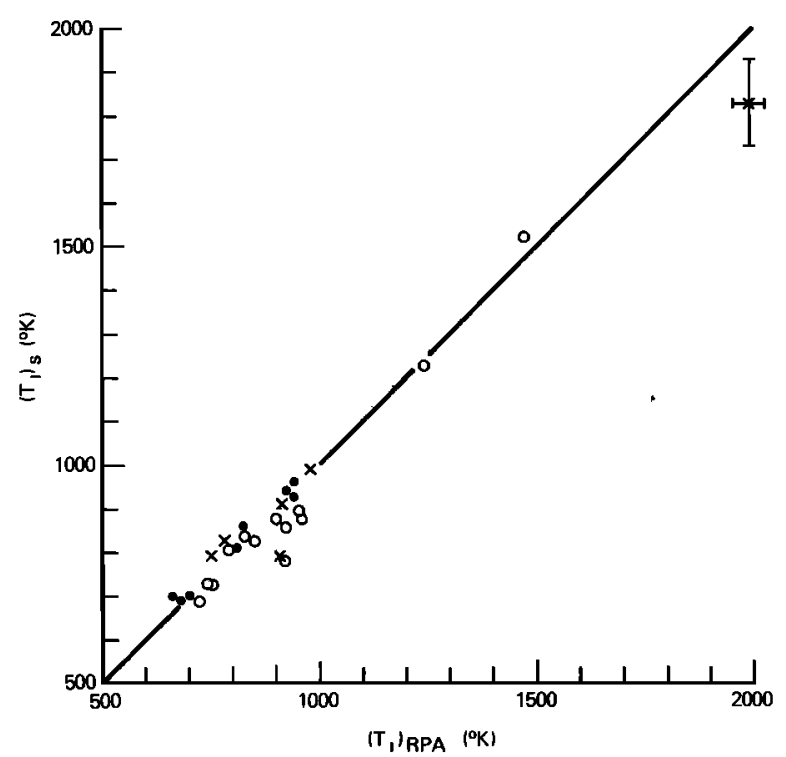

Fig. 5. Comparison of ion temperature measurements based on the AE-C planar retarding potential analyzer and three incoherent scatter facilities: Arecibo (open circles), Millstone Hill (crosses), and St. Santin (solid circles). The solid line at $45^{\circ}$ is shown to indicate the one-1o-one agreement reference position. The date, local time, position, and measurement uncertainty associated with each point are given in Table 1 . The average values for $\left(T_{i}\right)_{\mathrm{RPA}} /\left(T_{i}\right)_{5} \pm \sigma /(n)^{1 / 2}$ are the following: $0.981 \pm 0.008$ at St. Santin, $1.02 \pm 0.03$ at Millstone Hill, $1.03 \pm 0.01$ at Arecibo, and $1.02 \pm 0.01$ when all of the data are averaged together.

dinal corrections were available for all comparisons. Indeed, three of the five Arecibo comparisons in which the percentage difference was approximately $10 \%$ or greater corresponded to longitudinal separations of less than $3^{\circ}$ (see Figure $2 b$ ); one of these comparisons, however, was the high-altitude $(1811 \mathrm{~km})$ comparison (see Figure $2 c$ ), which had a large uncertainty associated with $\left(T_{e}\right)_{p}$ (see Table 1).

Low-and mid-latitude $T_{l}$ comparisons. The comparison between $\left(T_{i}\right)_{\mathrm{RPA}}$ and $\left(T_{t}\right)_{s}$ for the above three stations, as detailed in Table 1 , is shown in Figure 5. The average agreement between the in situ satellite measurements and the remote ground-based measurements is within a few percent at each of the stations. The average values for $\left(T_{i}\right)_{\mathrm{RPA}} /\left(T_{i}\right)_{s}$ were 0.98 , $1.02,1.03$, and 1.02 for St. Santin, Millstone Hill, Arecibo, and the combined data set from the three stations, respectively. This agreement is compatible with the estimated accuracy of the two techniques.

In situ comparisons of $T_{e}$ and $T_{t}$. In addition to the comparisons that can be made between the ground-based and the in situ measurements it is obviously possible to make direct comparisons between the satellite measurements of $T_{e}$ and $T_{i}$. When the $F$ region is in eclipse at low altitude and low latitude to mid-latitude, one might expect that thermal equilibrium should be very nearly established and that $T_{t} \simeq T_{e} \simeq T_{n}$. Five of the orbits listed in Table 1 (orbits 6442, 6506, 6522, 4484, and 4500 ) have been examined with regard to this internal consistency, and the mean value of $\left(T_{e} / T_{i}\right)$ for these data is approximately 1.06 . On these orbits, $\left(T_{e}\right)_{g}=\left(T_{l}\right)_{8}$ within their statistical error bars. The electron and ion temperatures for three of these orbits are plotted in Figures $6 a-6 c$. The steep rise in $T_{e}$ at the far left of the Arecibo plot in Figure $6 c$ is associated with solar UV heating (a similar rise occurred off the scale to the left in Figure $6 b$ ), whereas the similar rise in the St. Santin plot (Figure $6 a$ ) is presumably caused by high-latitude $(L>3.2$ ) heating. Random variations in the satellite data are apparent at the $1 \%$ or the $2 \%$ level, but some of the large-scale features are seen in both $T_{e}$ and $T_{i}$, and these are most likely present in $T_{n}$ as well in the form of thermospheric waves, as has been observed by Reber et al. [1975].
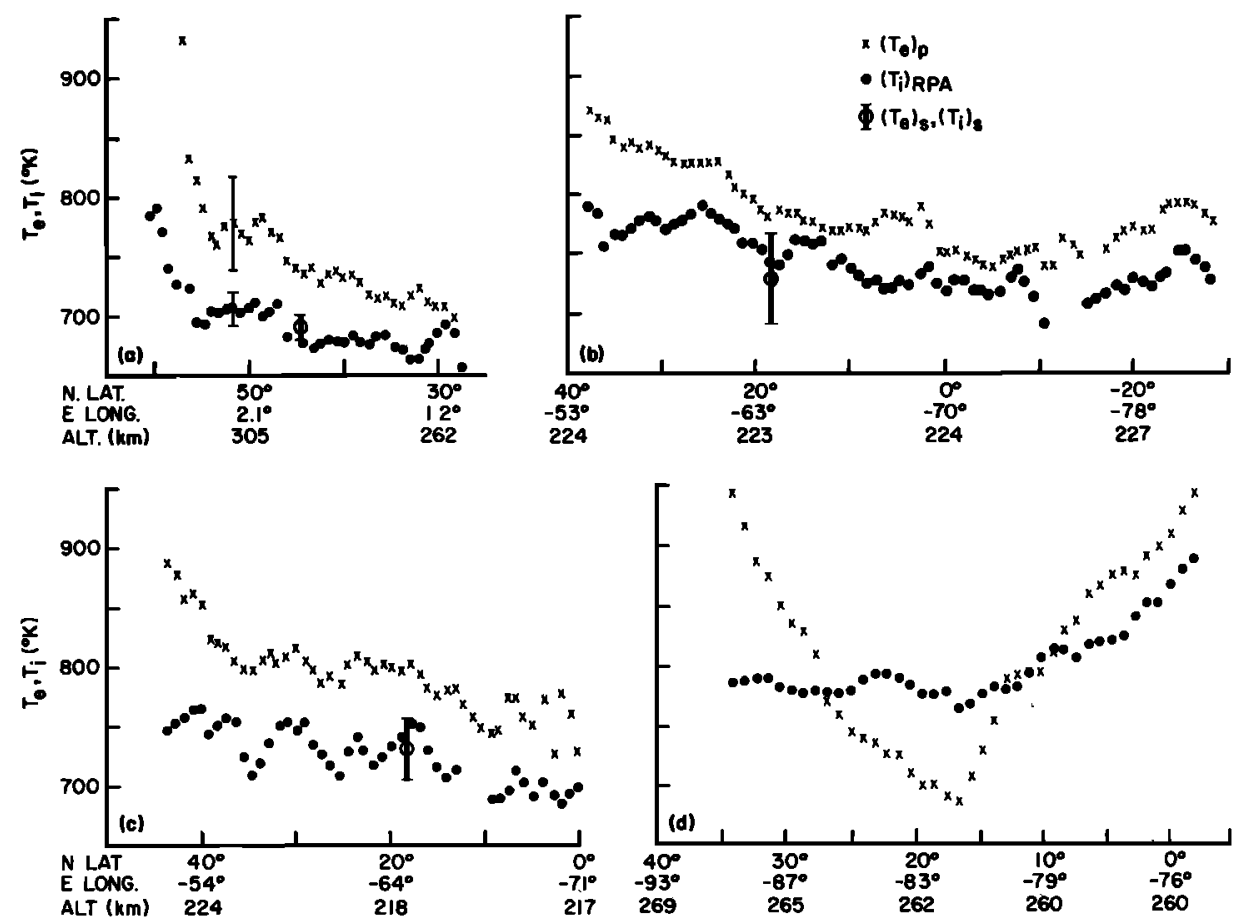

Fig. 6. Values of $\left(T_{i}\right)_{\mathrm{RPA}}$ and $\left(T_{e}\right)_{p}$ versus position along the orbital track for three nighttime orbits included in Table 1 ((a) orbit 4500 over St. Santin, (b) orbit 6442 over Arecibo, and (c) orbit 6506 over Arecibo) and (d) one nighttime orbit not included in the present temperature comparison data (AE-C orbit 4632 on December 20, 1974, crossing $20^{\circ}$ latitude at 0322 UT or 2151 LT on December 19). 

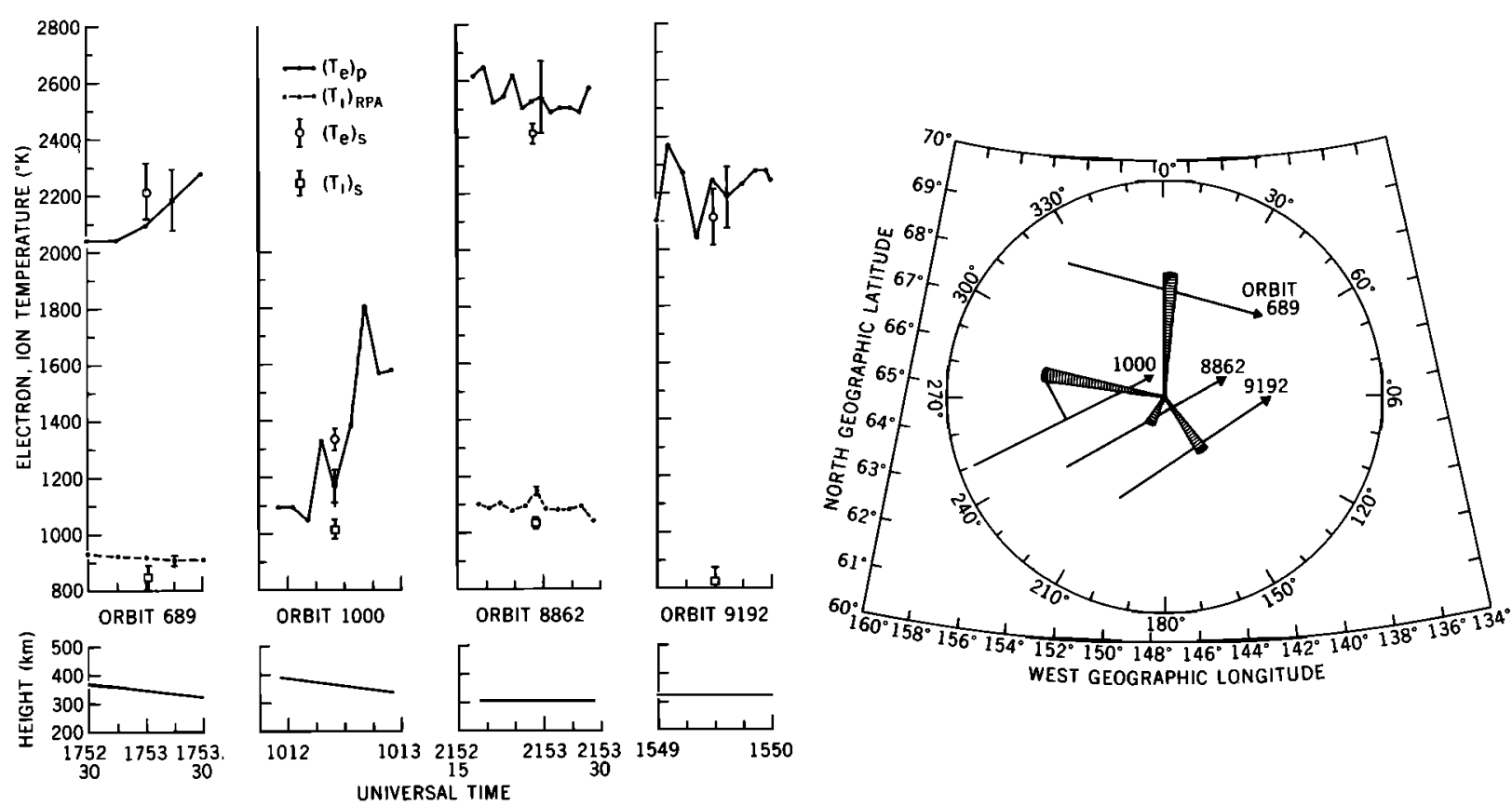

Fig. 7. Comparison of $\left(T_{e}\right)_{p}$ and $\left(T_{e}\right)_{8}$ for four passes and of $\left(T_{i}\right)_{\mathrm{RPA}}$ and $\left(T_{i}\right)_{\mathrm{g}}$ for two passes of AE-C over the Chatanika incoherent scatter facility. The incoherent scatter temperatures are based on an integration time of $30 \mathrm{~min}$ for orbit 689 (centered on 0803 LT), 10 min for orbit 1000 (centered on 2359 LT), 10.5 min for orbit 8862 (centered on 1200 LT), and 10.5 min for orbit 9192 (centered on 0608 LT). (A long integration time was possible during orbit 689 because the temporal variations were very small.) The AE-C altitude information is presented in the bottom graphs for each orbit and the latitude and longitude information is presented on the right-hand side with an azimuth circle (centered on Chatanika). The direction of the incoherent scatter beam, terminating at the AE-C altitude, is indicated in this circle for each orbit used in the temperature comparison. The perpendicular lines to the orbital track indicate the horizontal separation between the beam and AE-C $(23 \mathrm{~km}, 118 \mathrm{~km}, 8 \mathrm{~km}$, and $12 \mathrm{~km}$ for orbits $689,1000,8862$, and 9192 , respectively). The lengths of the orbital track vectors correspond to the motion of AE-C during the $1 \mathrm{~min}$ of satellite data shown in the four temperature versus UT graphs. The indicated universal times correspond to February 16, 1974, for orbit 689; March 16, 1974, for orbit 1000: September 9, 1975, for orbit 8862; and September 30, 1975, for orbit 9192.

If we assume that $\left(T_{l}\right)_{\mathrm{RPA}}$ and $\left(T_{i}\right)_{s}$ are correct, then the above comparisons imply that $\left(T_{e}\right)_{p}$ is about $6 \%$ high during the nighttime at low altitude and low latitude to mid-latitude. Such an excess could explain part of the difference observed between the satellite and incoherent scatter electron temperatures. An inspection of Figure $2 a$ indicates that these differences are greatest, on the average, during the nighttime hours. The average excess of $\left(T_{e}\right)_{p}$ over $\left(T_{e}\right)_{a}$ (which is $4 \%$ when all of the comparisons are considered) is $9 \%$ for the ten nighttime low-altitude comparisons and $2 \%$ for the remaining daytime comparisons. We have no evidence that $\left(T_{e}\right)_{p}$ is $6 \%$ high under all conditions. Indeed, if a $-6 \%$ correction is applied to all $\left(T_{e}\right)_{p}$ values, then the satellite-incoherent scatter electron temperature comparisons would be in better agreement at Millstone Hill but in worse agreement (and in the opposite sense) at A recibo and St. Santin.

The in situ measurements do not always indicate $T_{e}>T_{t}$ under the above conditions. Many examples have been found in which $T_{e}<T_{l}$. Figure $6 d$ shows such a case where this condition existed for more than $10^{\circ}$ of latitude and where the electrons were able to cool to a temperature about $10 \%$ less than the ion temperature. This condition of $T_{e}<T_{l}$ has also been observed (but with a smaller magnitude) in the incoherent scatter data from St. Santin and has been attributed to downward conduction to low-temperature regions [Mazaudier and Bauer, 1976].

High-latitude $T_{e}$ and $T_{i}$ comparisons. A different format is used to present the results of the AE-C-Chatanika com- parisons because of the great variability of $\left(T_{e}\right)_{p}$ along the satellite path in the high-latitude region. The results are shown for four different passes in Figure 7, where the AE-C temperatures are presented as a function of universal time and the incoherent scatter temperatures are plotted at the UT centered on the time interval used for data integration. The AE-C orbital information is also shown together with the direction of the incoherent scatter beam. The comparisons indicate remarkable agreement between the AE-C temperatures and the incoherent scatter temperatures in spite of the large spatial fluctuations observed by $\mathrm{AE}-\mathrm{C}$ and the temporal variations observed by Chatanika.

\section{SUMMARY}

Very good agreement was obtained between the AE-C determinations of $T_{t}$ and the ground-based measurements. This finding is consistent with an earlier comparison with Ogo 6, which had a similar RPA sensor. The AE-C $T_{e}$ determinations were compared with incoherent scatter determinations separately for each ground station. The AE-C probe temperature exceeded the incoherent scatter temperature by an average of $4 \%$, the agreement being better at St. Santin (3\% excess) and Arecibo ( $2 \%$ excess) than at Millstone Hill ( $11 \%$ excess). The variation in the comparison results between locations may have a geophysical origin. The AE-C and Chatanika measurements agree with one another (for both $T_{e}$ and $T_{t}$ ) well within the accuracy of the comparisons (approximately 10\%), considering the existing spatial and temporal variations. Direct com- 
parisons of the satellite measurements of $\left(T_{e}\right)_{p}$ and $\left(T_{i}\right)_{\mathrm{RPA}}$ when the two temperatures were expected to be equal generally indicated that $\left(T_{e}\right)_{p}$ exceeded $\left(T_{t}\right)_{\mathrm{RPA}}$ by about $5 \%$, although exceptions were found where the reverse condition was true.

Although good agreement was found between the AE-C electrostatic probe and incoherent scatter electron temperatures, no explanation has been found for some of the earlier comparisons which yielded significantly different temperatures. The following differences between the comparisons may have contributed to the improved agreement found in this study.

1. The present comparisons were made at lower altitudes (AE-C provides the lowest-altitude satellite measurements to date).

2. The present investigation offered more cases in which the two sets of observations were in good coincidence than were obtained in the previous satellite-ground station comparisons (the AE-C on-board propulsion enables orbit fixing over a particular station).

3. More comparisons were available from each station than in previous studies (AE-C orbit predictions are transmitted to the incoherent scatter stations, and a high priority is given to correlative studies in the AE program).

The measurement and data analysis techniques have undergone continual development over the years, and no doubt these effects too have contributed to the excellent agreement in the results presented here. We can now proceed to the task of combining the vertical incoherent scatter temperature profiles with the horizontal (AE-C satellite) profiles to obtain a threedimensional temperature field.

Acknowledgments. We are grateful to H. C. Brinton and J. H. Hoffman for access to their AE-C ion composition data.

The Editor thanks J. V. Evans and T. E. VanZandt for their assistance in evaluating this paper.

\section{REFERENCES}

Benson, R. F., Simultaneous in situ electron temperature comparison using Alouette 2 probe and plasma resonance data, J. Geophys. Res., 78, 6755-6759, 1973.

Benson, R. F., and W. R. Hoegy, The effect of an isotropic nonequilibrium plasma on electron temperature measurements, J. Geophys. Res., 78, 4702-4706, 1973.

Brace, L. H., and J. P. McClure, Comparisons of equatorial rocket probe and radar observations (abstract), Eos Trans. AGU, 52, 290, 1971.

Brace, L. H., H. C. Carlson, and K. K. Mahajan, Radar backscatter and rocket probe measurements of electron temperature above Arecibo, J. Geophys. Res., 74, 1883-1885, 1969.

Brace, L. H., R. F. Theis, and A. Dalgarno, The cylindrical electrostatic probes for Atmosphere Explorer-C, -D, and -E, Radio Sci. 8, 341-348, 1973.
Carlson, H. C., and J. Sayers, Discrepancy in electron temperatures deduced from Langmuir probes and from incoherent scatter radars, J. Geophys. Res., 75, 4883-4886, 1970.

Dalgarno, A., W. B. Hanson, N. W. Spencer, and E. R. Schmerling, The Atmosphere Explorer mission, Radio Sci., 8, 263-266, 1973.

Evans, J. V., A comparison of rocket satellite and radar determinations of electron temperature at mid-latitudes, J. Geophys. Res., 70, 4365-4374, 1965.

Goldan, P. D., E. J. Yadlowsky, and E. C. Whipple, Jr., Errors in ion and electron temperature measurements due to grid plane potential nonuniformities in retarding potential analyzers, $J$. Geophys. Res., 78, 2907-2916, 1973.

Hanson, W. B., L. H. Brace, P. L. Dyson, and J. P. McClure, Conflicting electron temperature measurements in the upper $F$ region, $J$. Geophys. Res., 74, 400-401, 1969.

Hanson, W. B., D. R. Frame, and J. E. Midgley, Errors in retarding potential analyzers caused by nonuniformity of the grid plane potential, J. Geophys. Res., 77, 1914-1922, 1972.

Hanson, W. B., D. R. Zuccaro, C. R. Lippincott, and S. Sanatani, The retarding potential analyzer on Atmosphere Explorer, Radio Sci., 8 , 333-339, 1973.

Hoegy, W. R., Probe and radar electron temperatures in an isotropic nonequilibrium plasma, J. Geophys. Res., 76, 8333-8340, 1971.

Mazaudier, C., and P. Bauer, Nocturnal thermal disequilibrium of the $F_{2}$ region ionosphere at middle latitudes, J. Geophys. Res., 81, 3447-3451, 1976.

McClure, J. P., and B. E. Troy, Jr., Equatorial ion temperature: A comparison of conflicting incoherent scatter and Ogo 4 retarding potential analyzer values, J. Geophys. Res., 76, 4534-4540, 1971.

McClure, J. P., W. B. Hanson, A. F. Nagy, R. J. Cicerone, L. H. Brace, M. Baron, P. Bauer, H. C. Carlson, J. V. Evans, G. N. Taylor, and R. F. Woodman, Comparison of $T_{e}$ and $T_{t}$ from Ogo 6 and various incoherent scatter radars, J. Geophys. Res., 78, 197-205, 1973.

Oya, H., and R. F. Benson, A new method for in situ electron temperature determinations from plasma wave phenomena, $J$. Geophys. Res., 77, 4272-4276, 1972.

Reber, C. A., A. E. Hedin, D. T. Pelz, W. E. Potter, and L. H. Brace, Phase and amplitude relationships of wave structure observed in the lower thermosphere, J. Geophys. Res., 80, 4576-4580, 1975.

Sagalyn, R. C., and R. H. Wand, Daytime rocket and Thomson scatter studies of the lower ionosphere, J. Geophys. Res., 76, 3783-3799, 1971.

Spencer, N. W., L. H. Brace, and D. W. Grimes, The Atmosphere Explorer spacecraft system, Radio Sci., 8, 267-269, 1973.

Taylor, G. N., and G. L. Wrenn, Comparisons of simultaneous satellite and ground-based measurements of ionospheric parameters, Planet. Space Sci., 18, 1663-1666, 1970.

Wrenn, G. L., D. H. Clark, W. J. Raitt, and H. C. Carlson, Modulation Langmuir probe and incoherent scatter radar measurements of ionospheric electron temperature, J. Atmos. Terr. Phys., 35, 405-413, 1973.
(Received June 16, 1976; accepted August 25, 1976.) 